\title{
Fault Tolerant Control of Induction Motor
}

\author{
Khalaf Salloum Gaeid \\ Dept. of Electrical Engineering University of Malaya \\ Lembah Pantai, 50603, Kuala Lumpur, Malaysia \\ E-mail: salimhazim2010@gmail.com \\ Hew Wooi Ping \\ Dept. of Electrical Engineering University of Malaya \\ Lembah Pantai, 50603, Kuala Lumpur, Malaysia
}

Received: April 21, 2011

Accepted: May 4, 2011

doi:10.5539/mas.v5n4p83

\begin{abstract}
The principle of vector control of electrical machines is to control both the magnitude and the phase of each phase, current and voltage. MATLAB/Simulink has been performed for assessment of operating features of the proposed scheme. Proportional Integral (PI) speed controller is designed in this paper. Test response of the developed variable speed drive along with the simulated response is given and discussed in detail for torque and speed. Fault tolerant fundamental is applied to the system when it is subject to a system fault. Two faults are investigated in this paper, stator short winding and broken rotor bar. The induction motor operates with acceptable performance in both speed and torque. The induction motor modeling along with the vector control fault tolerant scheme is investigated to show the optimal response of the control system
\end{abstract}

Keywords: field oriented control, fault tolerant control, induction motor, PI controller vector control

\section{Nomenclature}

$$
\begin{array}{lc}
f & \text { Friction coefficient } \\
i_{d r}, i_{q r} & \text { d,q-axis rotor current components } \\
i_{d s}, i_{q s} & \text { d,q-axis stator current components } \\
j & \text { Total inertia } \\
k_{i} k_{p} & \text { Integral and proportional controller } \\
L_{r} & \text { Rotor self inductance } \\
L_{s} & \text { Stator self inductance } \\
L_{m} & \text { Magnetizing inductance } \\
p & \text { The number of pair poles } \\
T_{e}, T_{l} & \text { Electromagnetic and load torques } \\
V_{d s} V_{q s} & \text { d,q -axis stator voltage components } \\
V_{d r}, V_{q r} & \text { d,q -axis rotor voltage components } \\
\omega_{m e c h} & \text { Mechanical (output) angular speed } \\
\varphi_{d s}, \varphi_{q s} & \text { d,q -axis stator flux components } \\
\varphi_{d r}, \varphi_{q r} & \text { d,q -axis rotor flux components } \\
\rho & \text { Any positive number } \\
* & \text { Reference value } \\
R_{s h} & \text { Stator short circuit winding }
\end{array}
$$




$$
\begin{array}{lc}
R_{\text {org }} & \text { Original stator resistance } \\
R_{b r k} & \text { Rotor broken bar } \\
z_{n b} & \text { Rotor bar number } \\
N_{S} & \text { Stator phase winding number }
\end{array}
$$

\section{Introduction}

Nowadays, there is a demand for high performance electric drives capable of accurately achieving speed command. This necessarily leads to more sophisticated control methods to deal with such an issue. A special attention was directed toward the induction motor because of known reasons such as: size, cost and efficiency [Vas, 1990].

Vector control techniques have been widely used for the high performance drive of induction motors. As in DC motor torque, the control of induction motor is achieved by controlling torque and flux components independently [M. Boussak and K. Jarray, 2006].

[Sedat Sunter et al, 2003] have described the converter fed $2.5 \mathrm{KW}$ induction motor using vector control of the closed loop matrix converter system.

[Schofield et al, 1998] described direct torque control as a method of controlling an inverter and induction motor which provides excellent performance without rotor position sensing; that is, it is a high performance sensor-less system.

The advances in signal processing technology have made it possible to utilize vector control principles and the inverter fed induction motor in the industrial efficiently.

The induction motor requires a variable-frequency three-phase source for variable speed operation. One can realize this source by using a power converter system consisting of a rectifier connected to an inverter through a DC link.

In some control schemes where a three-phase variable frequency current source is required, current control loops are added to force the motor currents to follow the sinusoidal input reference.

The inverter fed induction motor drive can be controlled with various schemes depending on the application, the desired performance and the controller design complexity.

The most utilized schemes are the stator V/F, the control stator currents, the open loop flux control Vector control (field-oriented control) and the direct torque control [Bose, B. K. 2002].

[Welchko et al, 2001] presented variable voltage and frequency motor drive system for a three-phase induction machine, in this drive system, the machine is excited by unidirectional stator currents shaped and sequenced in a way that a rotating air-gap flux is induced so that the machine can operate.

In vector or field oriented control, both the magnitude and the phase alignment of vector variables are controlled.

The vector control was invented in the beginning of $1970 \mathrm{~s}$, and this led to the demonstration that an induction motor can be controlled like a separately excited DC motor. This invention brought renaissance in the high performance of the control of AC drives.

The similarities between DC and vector control make it known as decoupling orthogonal or trans vector control [Archana S. Nanoty, and A. R. Chudasama, 2008].

Conventional Proportional-Integral (PI) controllers, designed using the classical control theory, are well suited to the control of linear processes whose exact model is known. However, the majority of physical systems usually contain non-linear relations that are difficult to model. On the other hand, to use a self tuning PI controller, an adequate drive model must be known [Ho, E. Y. Y. Sen, P. C, 1990 \& Ho, E. Y. Y. Sen, P. C, 1991].

[H. Moghbelli et al,2005] presented a vector control induction motor drive which is first simulated and then implemented in real time where a novel artificial neural network (ANN) based on wavelets (namely wave net) is used as a controller in order to make the system more robust.

[Sayed-Ahmed et al, 2007] have studied inter-turn short circuit in one phase of a stator winding of an induction motor energized by a vector-controlled drive.

[Mirafzal, B et al ,2004] have studied the diagnosis of the broken-bar faults in induction machines operating at the steady state using space vector.

[Karami, F et al, 2010] have studied the rotor broken bar in induction motor using Park's vector approach.

The system performance can be improved when the fault tolerant fundamental is applied, especially when it is subjected to a fault.

FTCS is a class of highly sophisticated control functions designed in a unified framework in order to maintain high levels of system integrity [Mufeed Mahmoud, 2008]. 
Fault tolerant control (FTC) has a lot of attention during the last twenty years in most of the industrial applications such as: flight control, machines, power plants, computer networks and refineries.

There are two types of FTC; the passive type and active type. The methods that deal with active fault tolerant control (adaptive control) are linearization feedback, linear quadrature method, Pseudo inverse method, Eigen structure assignment method, neural network, control law rescheduling, model predictive control MPC, HY, norm optimization and four parameter controller[Khalaf Salloum Gaeid et al,2011\& Khalaf Salloum Gaeid et al,2010].

[M.E. Romero et al, 2010] have presented the fault-tolerant vector control of induction motors using the multi-sensor switching strategy, [D. Casadei et al,2010] has studied a direct field oriented control (FOC) drive and synchronous current regulators have been implemented, and its behavior has been analyzed in a healthy and a faulty condition.

\section{Vector Control of the Induction Motor}

Vector control of the squirrel cage induction motor is considered a fast response and a high performance method to achieve variable speeds using a variable frequency source as shown in Figure 1.

In the vector control method, the induction motor can be operated like a separately excited DC motor for high performance applications. To satisfy better performance, there are a lot of speed closed loop systems that have been improved. However, the desired drive specification still cannot be perfectly satisfied and/ or their algorithms are too complex [J.L. Silva Neto et al, 1996] as shown in Figure 2.

Vector control is one method used in variable frequency drives to control the torque (and thus finally the speed) of the three phases $\mathrm{AC}$ electric motors by controlling the current fed to the machine as it can be shown in the Eq1-Eq9.

Vector controlled machines need two constants as input references: the torque component (aligned with the q-axis coordinate) and the flux component (aligned with d-axis coordinate), it is simply based on the projections of the control structure handling instantaneous electrical quantities which is yields an accurate control in both the steady state and the transient response, and this is not depending on the mathematical model bandwidth of the induction motor.

The control problems can be solved using this technique, in the following ways:

- The stator current (torque and flux) components can be reached easily

- Remove the difficulties of applying the direct torque control [Texas Instruments Europe, 1998].

There are two different strategies in the vector control to get the rotor flux direct and indirect vector control.

- Rotor flux vector is either measured by a flux sensor mounted in the air-gap or measured using the voltage equations starting from the electrical machine parameters.

- Rotor flux parameter can be calculated by a direct rotor speed measurement.

The condition for applying the vector control in the induction motors is that the dynamic model equations are required in order to calculate and control the variables [AN2388 report, 2006].

\subsection{The Model of Induction Motor}

The d-q dynamic model of squirrel cage induction motor with a reference frame fixed to the stator is given by

$$
\begin{aligned}
& V_{s}=R_{s s}^{i}+\frac{d \lambda_{s}}{d t}+j \omega_{s} M \lambda_{s} \\
& V_{r}=R_{r r}^{i}+\frac{d \lambda_{r}}{d t}+\left(\omega_{s}-\omega_{r}\right) M \lambda_{r}
\end{aligned}
$$

The electromagnetic torque is found as

$$
\begin{aligned}
& T_{e}=\frac{2 p L_{m}}{3 L_{r}}\left(i_{q s} i_{d r}-i_{d s} i_{q r}\right) \\
& T_{e}=\frac{2 p L_{m}}{3 L_{r}}\left(i_{q s} \varphi_{d r}-i_{d s} \varphi_{q r}\right) \quad \text { Where } \\
& \varphi_{d s}=\underset{r d r}{i}+L_{m d s}{ }^{i}
\end{aligned}
$$

The field orientation is based on the following assumption:

$$
\begin{aligned}
& \varphi_{q r}=0 \\
& \varphi_{d r}=\text { const ant }
\end{aligned}
$$


The field orientation control (vector) performs the following calculations

$$
\left[\begin{array}{c}
i_{q s} \\
i_{d s}
\end{array}\right]=\left[\begin{array}{ll}
\cos \varphi_{s} & \sin \varphi_{s} \\
-\sin \varphi_{s} & \cos \varphi_{s}
\end{array}\right]
$$

$\mathrm{d}-\mathrm{q}$ to abc transformation is

$$
\left[\begin{array}{c}
i_{a s} \\
i_{b s} \\
i_{c s}
\end{array}\right]=\left[\begin{array}{cc}
1 & 0 \\
-0.5 & -\sqrt{3} / 2 \\
-0.5 & -\sqrt{3} / 2
\end{array}\right]\left[\begin{array}{c}
i_{q s} \\
i_{d s}
\end{array}\right]
$$

According to that, the rotor flux and the torque can be controlled individually through the stator current in the dq-axis so that the induction motor is transformed to the linear current / torque relationship.

2.2 PI Speed Controllers

The dynamic model of induction motor speed controller can be represented by the block diagram shown in Figure 3; the output of the speed controller is

$$
\omega_{S}(s)=\frac{p\left(T-T_{l}\right)}{j s+f}
$$

The PI (Proportional and Integral) regulator is well suited to regulating the torque and flux feedback to the desired values as it is able to reach a constant reference, by correcting both the P term $\left(k_{p}\right)$ and the I term $\left(k_{i}\right)$ which are respectively responsible for error sensibility and for the steady state error.

If $T_{l}=0$ the transfer function is as the following:

$$
\begin{gathered}
G(s) \frac{p\left(k_{p} s+k_{i}\right)}{J_{s^{2}}+\left(f+k_{p} p\right) s+k_{i} p} \\
p(s)={ }_{s}{ }^{2}+\frac{f+{ }_{k_{p}} p}{j}+\frac{k_{i} p}{j}=0
\end{gathered}
$$

$P(s)$ Is the characteristic equation of the $G(s)$ the expressions for $k_{p}$ and $k_{i}$ of the regulator is calculated by imposition of poles complexes combined with real part negative.

$s_{1,2}=\rho(-1 \pm j)$

$$
k_{p}=\frac{2 \rho j-f}{p}
$$

$k_{i}=\frac{2 \rho^{2} j}{p}$

For speed controller, an Integral Proportional (PI) speed controller has been designed to stabilize the speed control loop. The gains of both $\mathrm{P}$ and I are designed to get a damping ratio(less than unity) which can be satisfied by using $\left(k_{p}=8\right.$ and $\left.k_{i}=42\right)$ for a torque limit of $120 \mathrm{~N}$.m [Hakan C et al, 2007].Figure 3 shows the speed controller of the proposed scheme while Figure 4 shows the simplified transfer function of the system to satisfy the performance specifications.

It is quite evident that the response of the system according to the PI controller has a damping ratio of $\xi=0.707$ and the undamped natural frequency of $\omega_{m}=7.07 \mathrm{rad} / \mathrm{sec}$.

\section{Fault Tolerant control}

Fault tolerance is a fundamental requirement for dependable electric drives used in safety-critical applications or industrial processes where the very high costs of unplanned stops are unacceptable. In this paper, the fault tolerant control system as shown in Figure 5.The FTC is composed of protection and isolation units as shown in Figure 6 and Figure 7 respectively.

These units control the operation of speed and torque, so the system will continue even there is a fault. First the isolation unit tries to isolate the fault, if the fault increased beyond a certain value, the protection unit will stop the operation of the induction motor as it is depicted in the flow chart shown in Figure 8.

To test the fault tolerant algorithm, two faults are investigated; stator short winding and broken rotor bar. 
For the stator short circuit winding fault, the stator resistance of the induction motor is connected to the parallel with a variable resistance which is reduced according to the following formula:

$$
R_{\text {sh }}=0.1 R_{\text {org }}
$$

Rotor broken bar fault can be simulated by connecting three resistors with rotor resistance so that by increasing one of the rotor phase resistances, the broken rotor bar equivalent resistance can be computed as:

$$
R_{b r k} \cong(0.33 / 4) R_{r} z_{n b}^{/ N^{\wedge} 2}
$$

The external added resistance is changed into $0.001 \Omega$ steps which represents the difference between the reference rotor resistance and the original rotor resistance. The reference rotor resistance depends on the number of broken bars and the total number of rotor bars.

\section{Computer Simulation}

Computer simulations using Matlab/Simulink have been performed for an assessment of the operating features of the proposed scheme. The simulation involved a startup of an unloaded, $50 \mathrm{hp}, 460 \mathrm{~V}, 50 \mathrm{~Hz}$ as shown in Table 1. All pertinent mathematical models have been developed individually using Simulink blocks for the power, the electronic converters and the motor. The machine is initially operating in the steady state at no load $\left(T_{l}=0\right)$ at the speed $\omega_{\text {ref }}=80 \mathrm{rad} / \mathrm{sec}$. The transient response is due to step changes in the reference speed and the load torque. The estimated value of the rotor time constant $\left(T_{r}=L_{r} / R_{r}=0.1557 \mathrm{sec}\right)$ appearing in the theta calculator, differs from the actual value used for the motor parameters. The harmonic existing in the shaft torque is not very significant since the system has a large mechanical time constant. During the period 0.2 sec, the developed torque increases rapidly. This is due to the slip speed which is the maximum at the beginning and decreases as the speed of the motor is increased.

The classic vector control scheme consists of the torque and the flux control loops. For the vector control of induction motors, the rotor field orientation has the advantage of easy decoupling of the torque and flux control.

The induction motor is modeled in the common stator reference frame [M. Ben Mohamad et al, 2008]. The speed loop utilizes a PI controller to produce the direct axis currents id* as shown in Figure 9, which serves as the speed command. The derived quadrature -axis current iq* as shown in Figure 10, serves as the rotor flux command. These currents are then transformed via the dq2abc block into the current references ia,ib and ic fed into the current regulator.

The current-controlled inverter is made up of three hysteresis controllers. The Rotor flux field orientation is obtained in the theta calculator block [M. Riaz, 2001]. The system reaches the steady-state developed torque and speed after about $0.45 \mathrm{sec}$ and $0.3 \mathrm{sec}$ respectively as in Figure 11 and Figure 12. The motor response for step up in speed command, which changes from $80 \mathrm{rad} / \mathrm{sec}$ to $110 \mathrm{rad} / \mathrm{sec}$., when step changes in speed command, the motor runs at no load with speed command $80 \mathrm{rad} / \mathrm{s}$ for $0.01 \mathrm{sec}$ which is the reactivated time of speed isolation time starting and then increased to $110 \mathrm{rad} / \mathrm{sec}$ as shown in Figure 11.

The transient change of the developed torque takes $0.05 \mathrm{sec}$ as shown in Figure 12 which is the reactivated time start the isolation fault. The motor speed increases very rapidly due to higher value of slip speed at the start. Figure 13 shows the reference and the load torque of the induction motor which is noticed that the steady-state motor speed is reached after about $0.35 \mathrm{sec}$. Figure 14 shows trip times recovery of both speed and torque after applying fault tolerant algorithm when the system is subjected to the stator short winding and broken rotor bar faults .In this Figure the recovery trip time for the speed is $0.74 \mathrm{sec}$ and for the torque is 0.73 sec. Figure 15 shows trip times recovery of both speed and torque after applying fault tolerant algorithm when the system is subjected to the stator short winding fault. In this Figure, the recovery time of the speed and torque is 0.31 sec and $0.4 \mathrm{sec}$ respectively, which is less than the recovery time of the two faults.

\section{Conclusions}

The scalar control of induction motor drives has many drawbacks, including: slow response, unsuitable performance, torque ripple and impossibility of operation at all points of the speed torque curve, vector control is implemented on an induction motor drive to solve these imperfections. A three phase sinusoidal voltage is converted to DC voltage with the help of the universal diode bridge rectifier. The rectified voltage is fed to the voltage source inverter \& Current source inverter. The present research is directed to the formulation and experimental verification of parameter compensation schemes in the vector Controlled induction motor drives. Voltage source inverters which dominate modern adjustable speed AC drives have certain disadvantages. In particular, the high switching rate needed for good quality of the current fed to the motor causes losses and electromagnetic interference. The short circuit stator winding and broken bar faults can have a significant effect on the induction motor working operation.

According to the results, the fault tolerant control algorithm was confirmed effectively.

Fault tolerant control in the induction is very important to maintain system performance at an acceptable level. 
The algorithm used is very effective and has been succeeded to maintain both speed and torque. The combination of both isolation and protection units was a very effective way to prevent the degradation in the system performance

\section{References}

AN2388 Application note, Sensor Field Oriented Control (IFOC) of Three-Phase AC Induction Motors Using ST10F276, 2006.

Archana S. Nanoty, and A. R. Chudasama. (2008). Vector Control of Multimotor Drive, Proceedings of World Academy of Science, Engineering and Technology, Vol. 35, pp 2070-3740.

Bose, B. K. (2002). Modern Power Electronics and AC Drives. Prentice-Hall, N. J.

D. Casadei, M. Mengoni, G. Serra, A. Tani and L. Zarri. (2010). Theoretical and Experimental Analysis of Fault-Tolerant Control Strategies for Seven-Phase Induction Motor Drives, International Symposium on Power Electronics Electrical Drives Automation and Motion (SPEEDAM),1628 - 1633.

Field Orientated Control of 3-Phase AC-Motors, Literature Number BPRA073, Texas Instruments Europe, February, 1998.

Ho, E. Y. Y. Sen, P. C. (1990). A Microprocessor-Based Induction Motor Drive System Using Variable Structure Strategy with Decoupling, IEEE Transactions on Industrial Electronics 37,227-235.

Ho, E. Y. Y. Sen, P. C. (1991). Control Dynamics of Speed Drive System Using Sliding Mode Controllers with Integral, IEEE Transactions on Industrial Application 27, 883-892.

H. Moghbelli, A. Rahideh, A. A. Safavi. (2005). Vector Control of Induction Machines Using Wave net Based Controller for Traction Applications, Iranian Journal of Science \& Technology, Transaction B, Engineering,29(B1).

Hakan C, alıs, Abd ulkadir C, akır. (2007). Rotor bar fault diagnosis in three phase induction motors by monitoring fluctuations of motor current zero crossing instants, Electric Power Systems Research77,385-392.

J.L. Silva Neto, Hoang Le-Huy. (1996). Fuzzy Logic Based Controller for Induction Motor Drives, IEEE, IECON, 631-634.

Karami, F.; Poshtan, J; Poshtan, M. (2010). Broken bar fault detection in induction motors based on modified winding Function, IEEE International Conference on Control Applications, 1951 - 1956.

Khalaf Salloum Gaeid,Hew Wooi Ping, Haider A.F.Mohamed. (2010). Diagnosis and Fault Tolerant Control of the Induction Motors Techniques a Review" Australian Journal of Basic and Applied Sciences, 4:2, 227-246.

Khalaf Salloum Gaeid, Hew Wooi Ping. (2011). Wavelet fault diagnosis and tolerant of induction motor :A review, International Journal of the Physical Sciences, 6 (3), pp. 358-376.

Khalaf Salloum Gaeid, Hew Wooi Ping. (2010).Induction motor fault detection and isolation through unknown input observer. Scientific Research and Essays, 5(20), pp. 3152-3159.

Mirafzal, B.; Demerdash, N.A.O. (2004) Induction machine broken-bar fault diagnosis using the rotor magnetic field space vector orientation, 38th IAS Annual Meeting. Conference, 3, 1847 - 1854.

Mufeed Mahmoud. (2008). Stability Conditions for Discrete Time Fault Tolerant Control Systems in Noisy Environments, IEEE International Conference on Control Applications Part of Multi-conference on Systems and Control San Antonio,498-503.

M.E. Romero, M.M. Seron, J.A. De Dona. (2010). Sensor fault-tolerant vector control of Induction motors, IET Control Theory Appl., 4:9, 1707-1724.

M. Ben Mohamad, M.Jemli M. Boussak \& M. Gossa. (2008). Speed Sensorless Vector Control of Single Phase Induction Motor, J. Automation\& System Engineering, ECM-13451 Marsiele Cedex 20.

M. Riaz. (2001). Simulation of Electric Machine and Drive Systems, University of Minnesota.

M. Boussak, K. Jarray. (2006). A High Performance Sensorless Indirect Stator Flux Orientation Control of Induction Motor Drive, IEEE trans. Ind. Electron,53,41-49.

N .Kalaiarasi and K.S.R .Anjaneyulu. (2007). Adaptive Vector Control of Induction Motor Drives, International Journal of Electrical and Engineering 1:2, 239-245.

Peter Vas. (1990).Control of AC Machines. (1st ed) .Clarondon Press Oxford University.

Sedat Sunter, Jon C. Clare. (2000). Feed Forward Indirect Vector Control of A Matrix Converter-Fed Induction Motor Drive, The International Journal for Computation and Mathematics in Electrical and Electronic Engineering 19:4, 974 - 986.

Schofield, J.R.G.. (1998). Speed Drives Using Induction Motors and Direct Torque Control, IEE Colloquium, 5/1 $-5 / 7$.

Sayed-Ahmed, A.; Sizov, G.Y.; Demerdash, N.A.O. (2007). Diagnosis of Inter-Turn Short Circuit for a Polyphase 
Induction Motor in Closed-Loop Vector-Controlled Drives, IEEE, 42nd IAS Annual Meeting, 2262 - 2268.

Welchko, B.A, Lipo, T.A. (2001). A Novel Variable-Frequency Three-Phase Induction Motor Drive System Using Only Three Controlled Switches, IEEE Transactions, 37(6), 1739 - 1745.

\section{Figures and Tables}

Table 1. Induction motor parameters

\begin{tabular}{|l|l|l|}
\hline No. & parameters & value \\
\hline 1 & Rated power(hp) & 50 \\
\hline 2 & Rated Voltage (volt) & 460 \\
\hline 3 & Speed reference(Rad/sec) & 110 \\
\hline 4 & Number of phases & 3 \\
\hline 5 & Number of Poles p & 4 \\
\hline 6 & Rated Frequency (Hz) & 50 \\
\hline 7 & Moment of Inertia j (kg.m^2) & 1.66 \\
\hline 8 & Stator Resistance Rs (Ohm) & 0.087 \\
\hline 9 & Rotor Inductance Lr (Henry) & 0.0335 \\
\hline 10 & Stator Inductance Ls (Henry) & 0.0335 \\
\hline 11 & Mutual Inductance Lm (Henry) & $34.7 \mathrm{e}-3$ \\
\hline
\end{tabular}

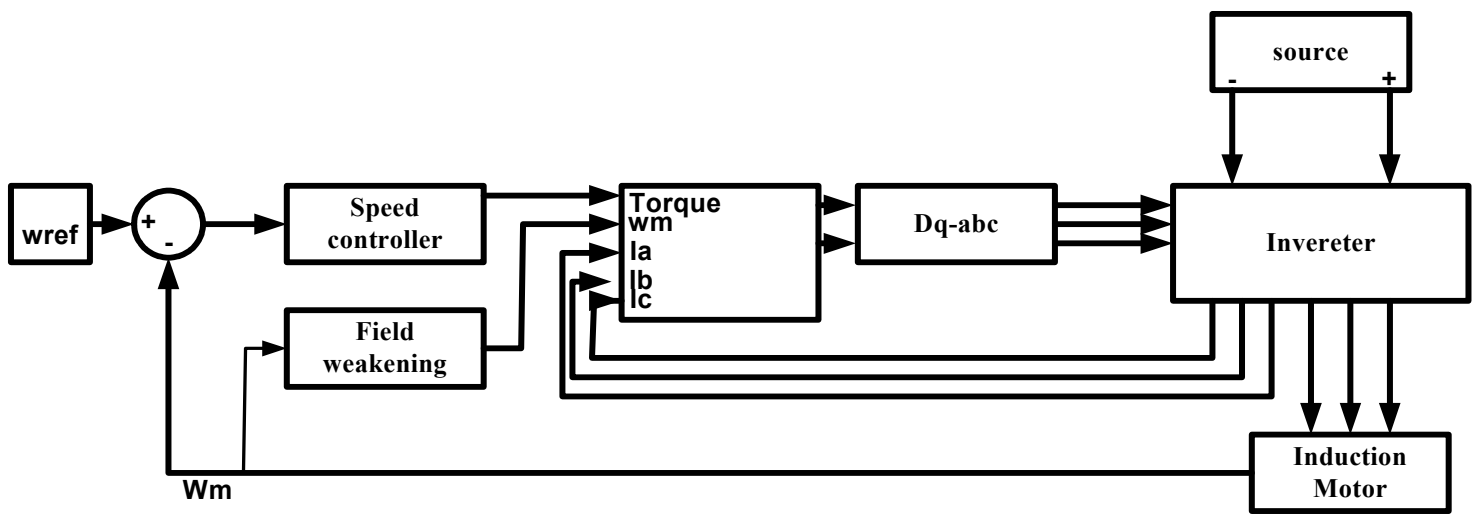

Figure 1. Vector control of induction motor

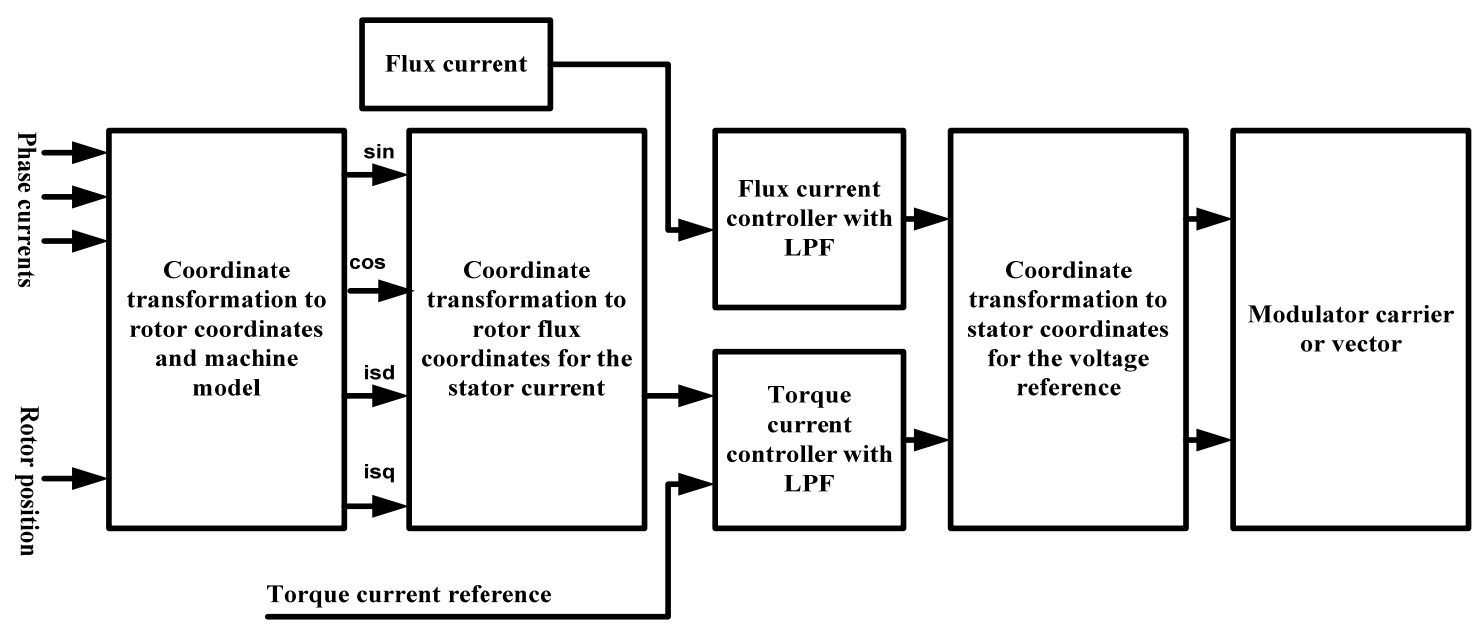

Figure 2. Block diagram of the vector control principle 


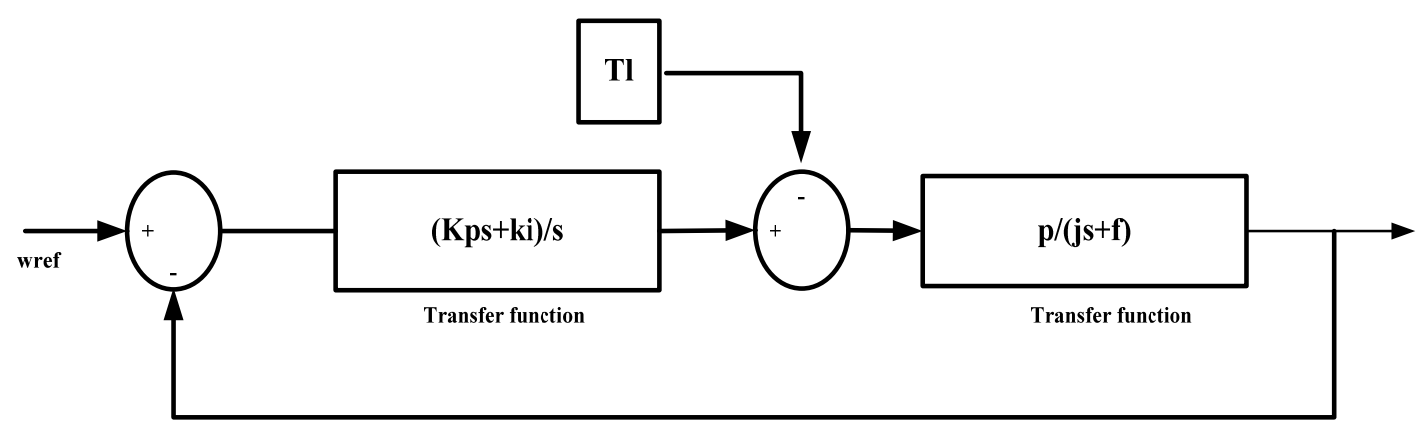

Figure 3. Block diagram of the simplified closed loop system

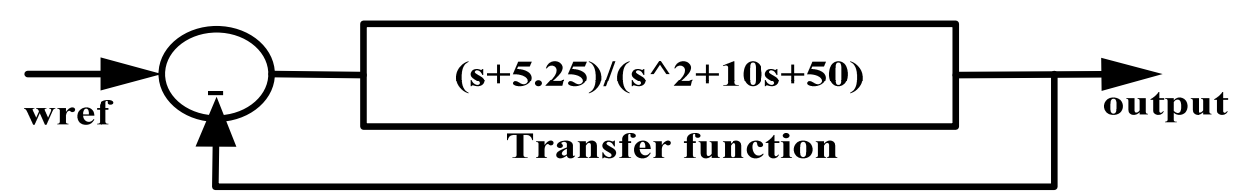

Figure 4. Closed loop of the speed controller loop 


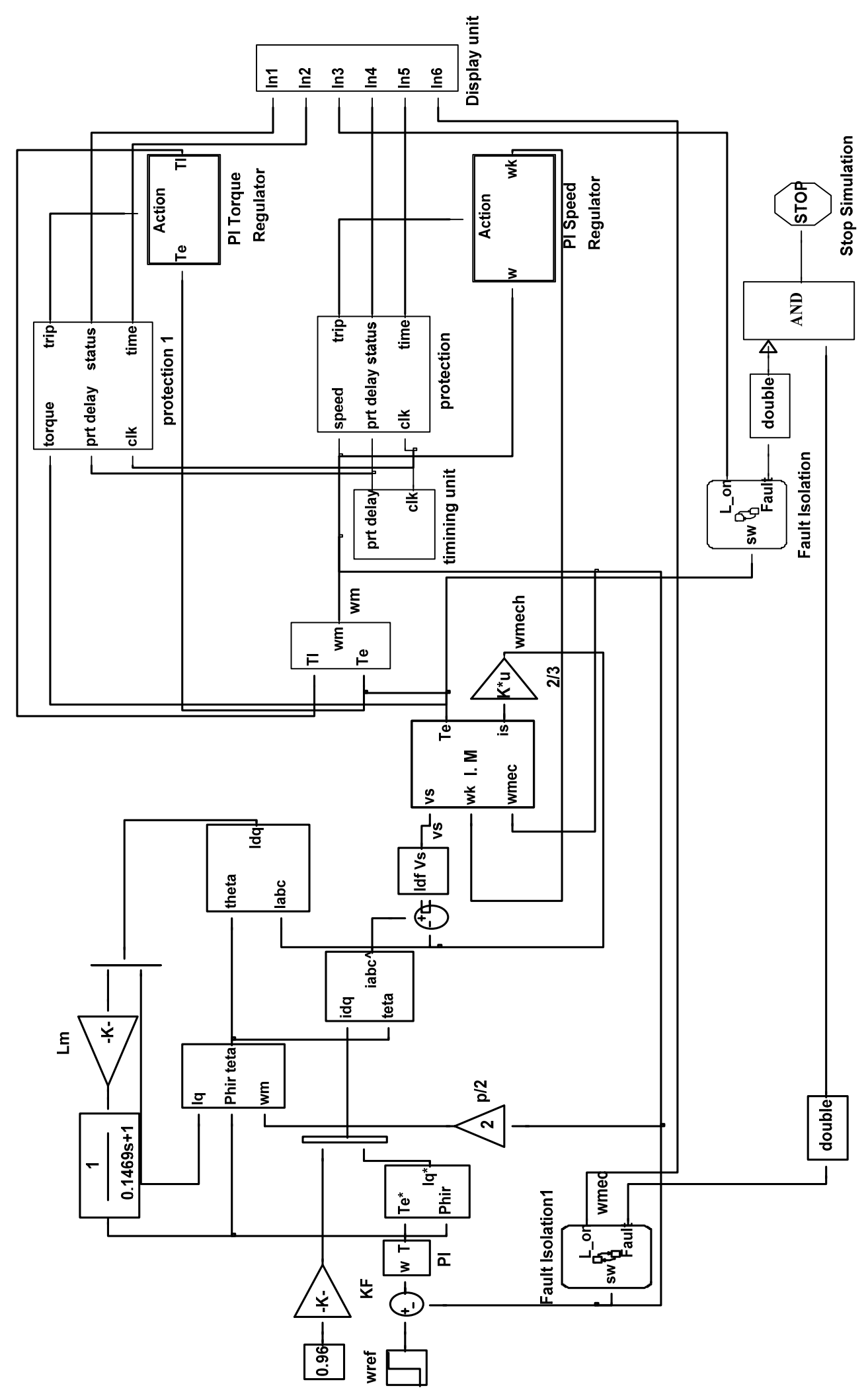

Figure 5. Proposed fault tolerant control of induction motor circuit 


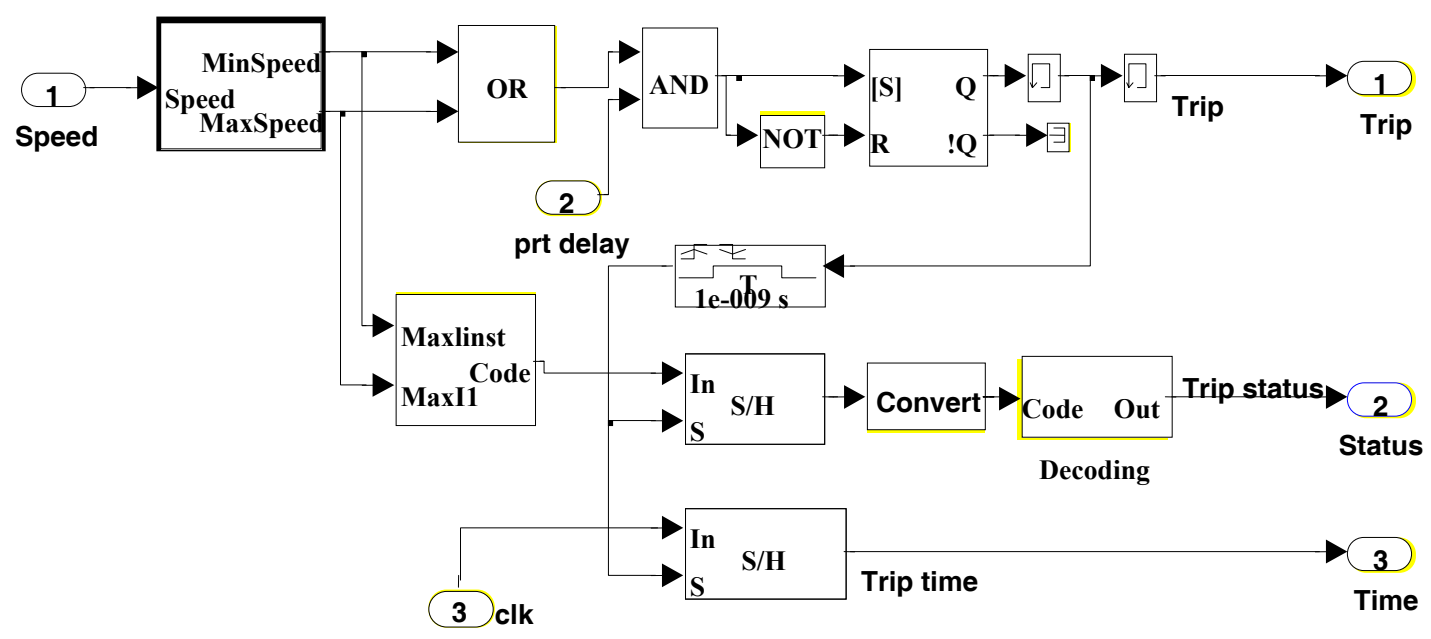

Figure 6. Speed Protection unit

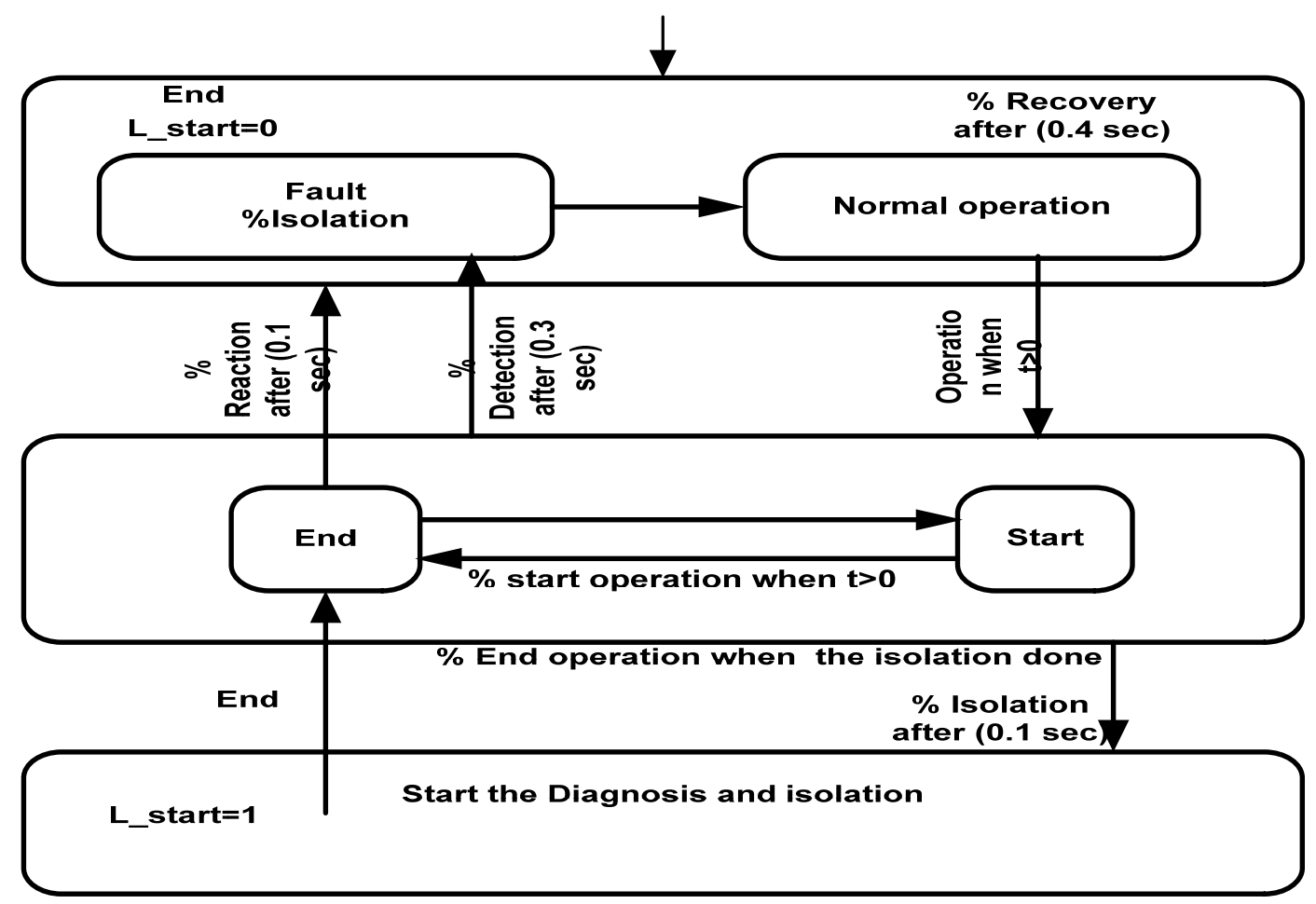

Figure 7. State flow unit for isolation and recovery 


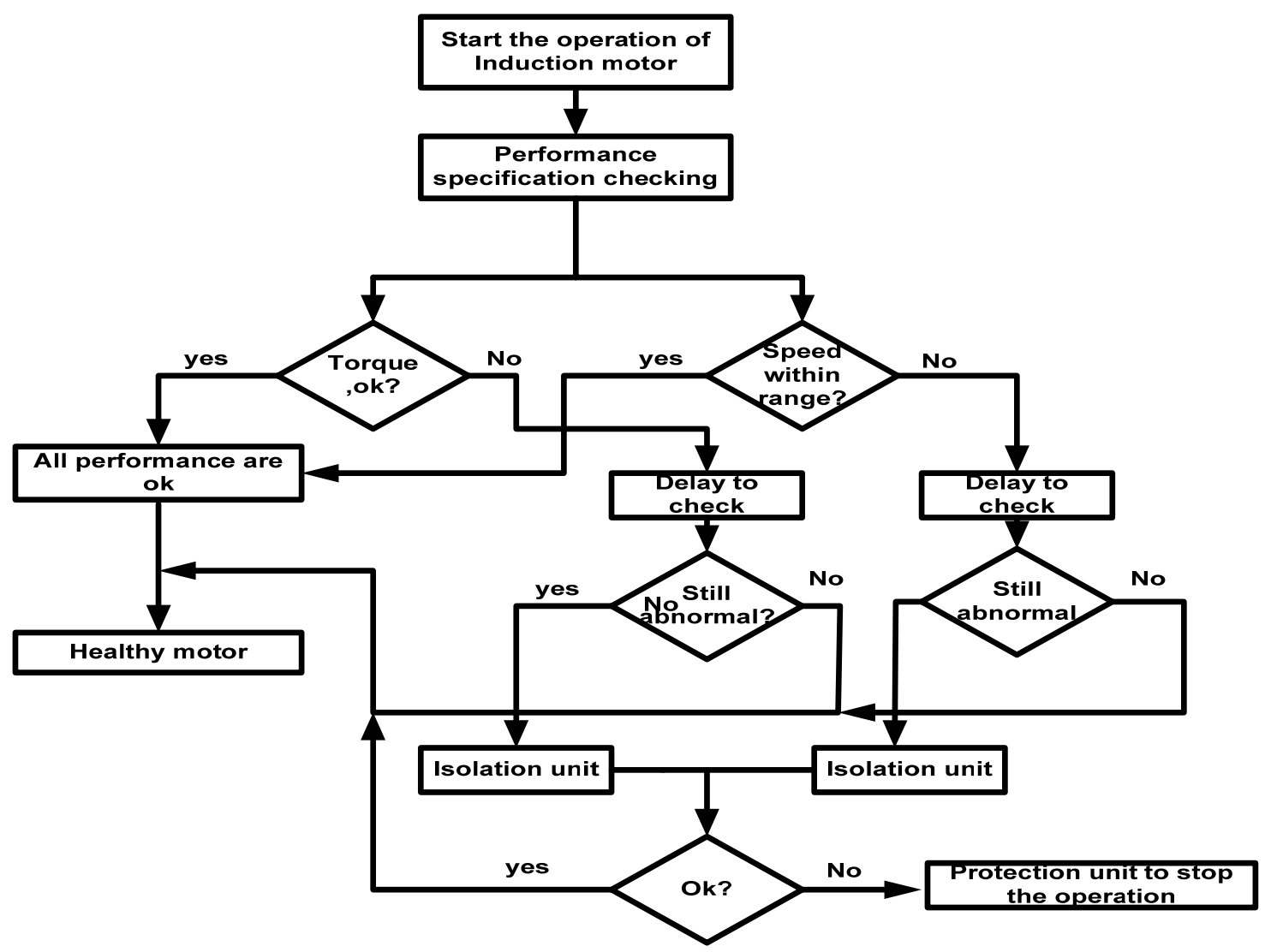

Figure 8. Flowchart of the work

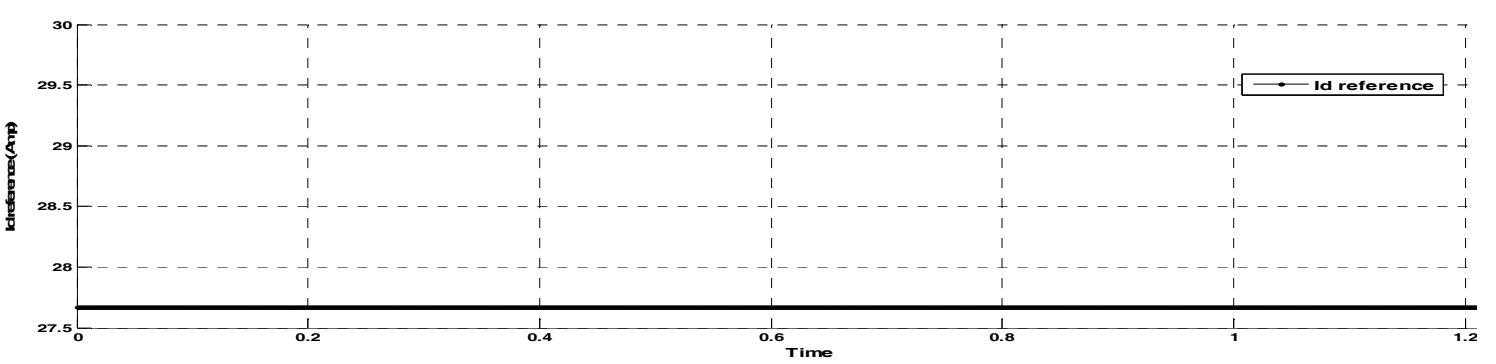

Figure 9. $\mathrm{I}_{\mathrm{d}} *$ reference of induction motor in healthy case

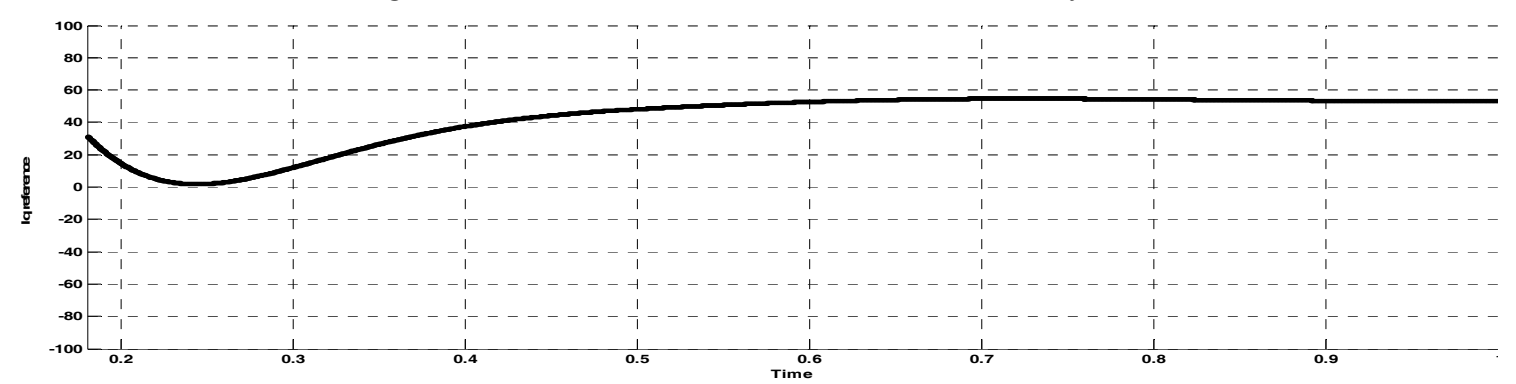

Figure 10. $\mathrm{I}_{\mathrm{q}} *$ reference of induction motor 

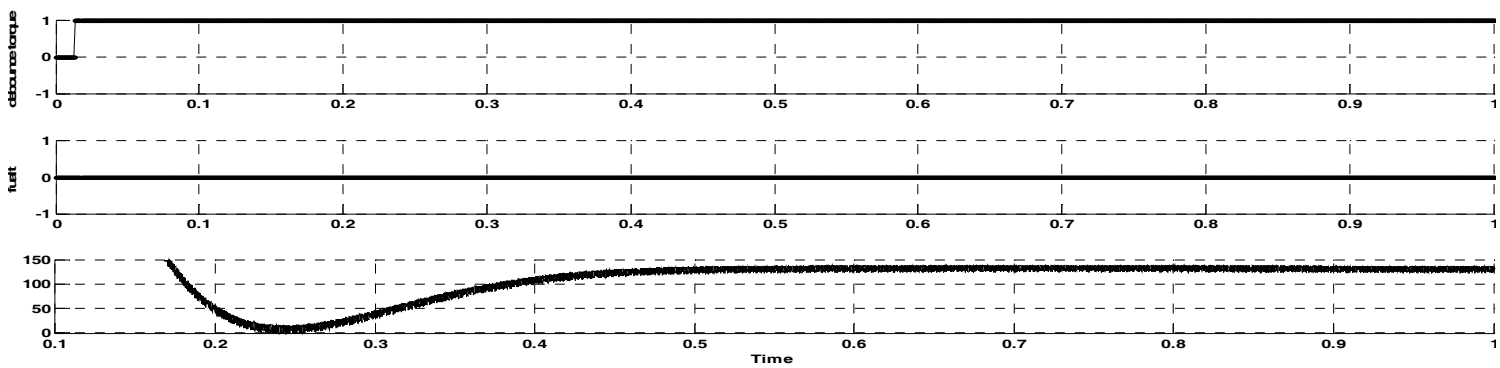

Figure 11. Isolation unit, reactivated torque (above), fault isolation (middle) and load torque
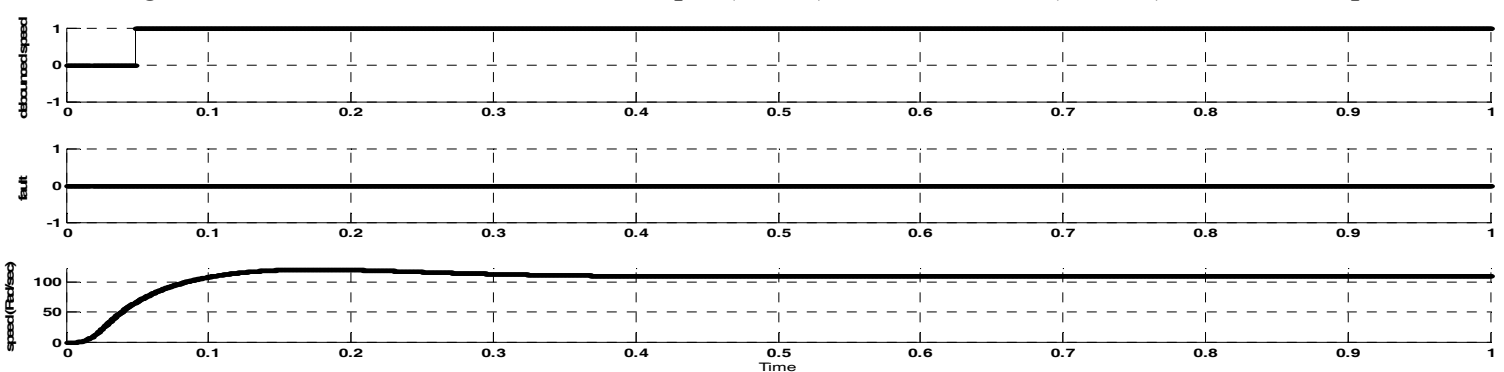

Figure 12. Isolation speed unit reactivated (above), isolated (middle) and output speed
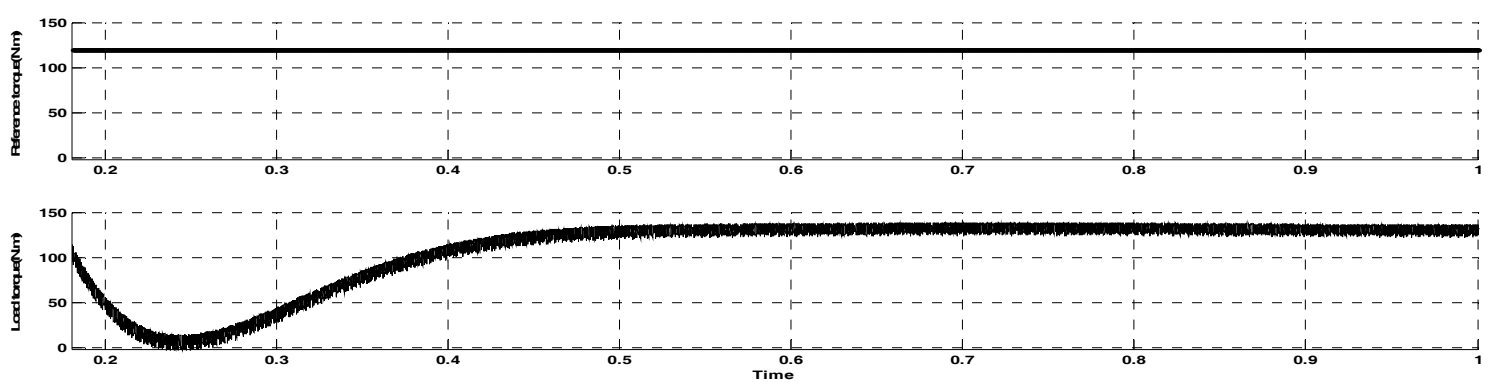

Figure 13. Reference torque (above) and the load torques of the induction motor

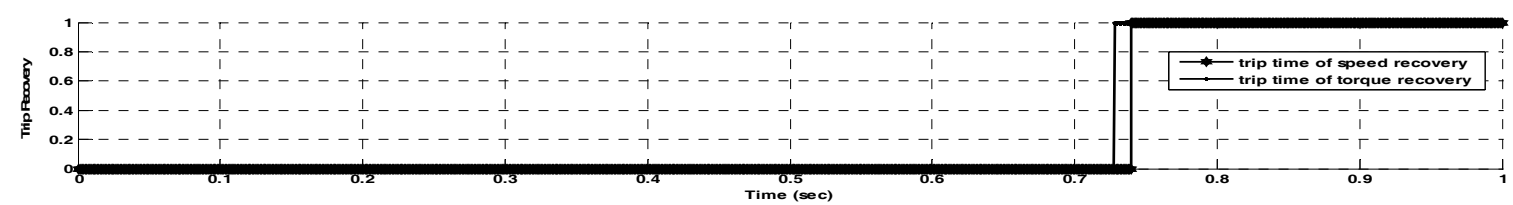

Figure 14.Trip times recovery of both speed and torque after applying fault tolerant algorithm (stator short winding and broken rotor bar faults)
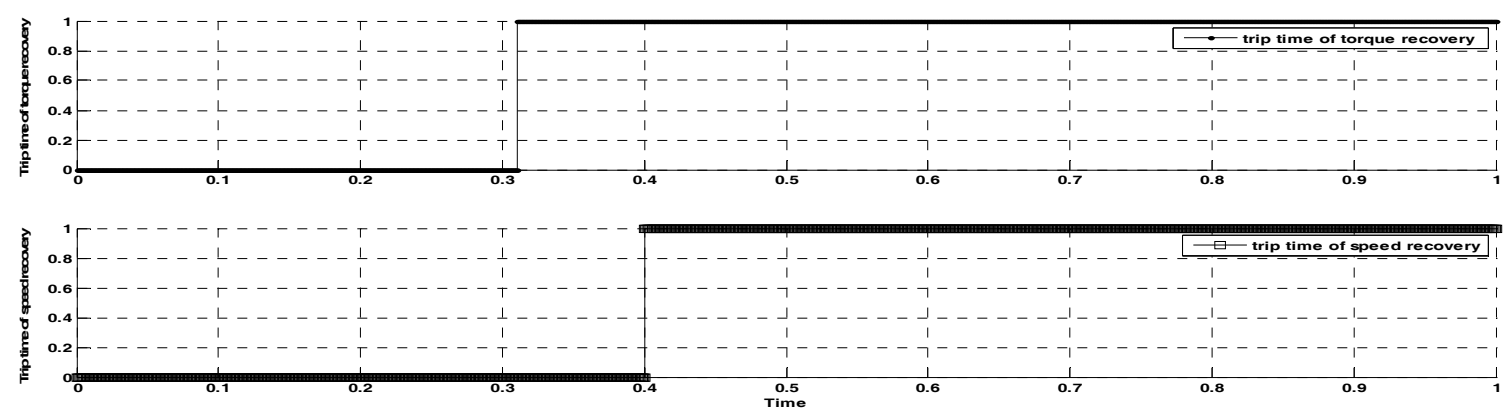

Figure 15. Trip times recovery of both speed and torque after applying FTC algorithm (stator short winding) 